\title{
A tal Cidade Média sempre foi execrada por mim, pelo direito que tenho de fazê-lo no Brasil, pois criei o monstro! ENTREVISTA COM A DRA. MARIA ADELIA SOUZA
}

\author{
Entrevistadores: \\ Sergio Sebastião Negri \\ sernegri@gmail.com \\ Universidade Federal de Mato Grosso, Rondonópolis, MT \\ Jeater W. M. C. Santos \\ jeater@ufmt.br \\ Universidade Federal de Mato Grosso, Rondonópolis, MT
}

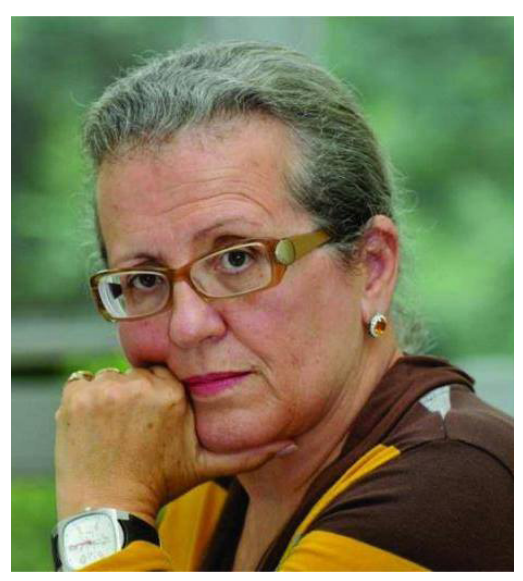

Professora titular de Geografia Humana da USP - Universidade de São Paulo (aposentada), é Bacharel e Licenciada em Geografia pela Faculdade de Filosofia, Ciências e Letras da USP (1962); pela DES Diplôme d'Études Superieures em Sciences Politiques et Economiques, na Universidade de Paris (1966), orientada pelo Professor Celso Furtado; Doutora em Geografia pelo Institut de Géographie, Universidade de Paris I (1975), orientada pelo Professor Michel Rochefort. Doutora honoris causa de várias universidades brasileiras e professora convidada em diversas universidades europeias e latino-americanas; cidadã honorária de vários municípios brasileiros; prefeita (1982 - 1985) e Chefe de Gabinete do Reitor da USP (1994 e 1995), em 2018 foi considerada uma das cientistas brasileiras pioneiras pelo CNPq. Foi a primeira reitora de Graduação da UNILA - Universidade da Integração Latino. Autora de vários livros sobre planejamento urbano e regional, metropolização e coautora da I Política Nacional de Desenvolvimento Urbano do Brasil, da I Política de Desenvolvimento Urbano e de Descentralização e Desconcentração Industrial do Estado de São Paulo.

madelia.territorial@gmail.com

Permitam-me, antes de começar a responder as questões formuladas pela entrevista, alertar o leitor que sou rigorosa na crítica e que mantenho esse rigor enquanto discuto no plano das ideias e nos coletivos produtores delas.

Aqui não pouparei a todas e todos nós, os geógrafos brasileiros, pela fragilidade do nosso conhecimento, produto da nossa história acadêmica e universitária formuladas - as opiniões, críticas e observações aqui exibidas - pela minha história de uspiana contumaz, aprimorada pela Geografia francesa do século XX, que me formou. Minhas críticas não se dirigem a pessoas, mas a ideias e instituições que lideram ou deveriam liderar e orientar no campo acadêmico e científico, com suas práticas, o processo de aprimoramento da produção e transmissão do conhecimento. 
No caso da disciplina geográfica, segundo minha análise, esse processo tomou sempre, basicamente, dois rumos para os quais alerto os leitores e peço que reflitam sobre isso:

... ou fomos ensinados a práticas de produção e transmissão do conhecimento geográfico ainda estacionadas no século XX, sob a influência da escola francesa em todas suas versões, da escola alemã quanto ao peso dos aspectos físicos do planeta, da escola quantitativista e, mais recentemente, a denominada geografia radical, ambas americanas, à qual, esta última, muitos geógrafos brasileiros liderados por Milton Santos, quando do seu retorno ao Brasil, aderiram na famosa reunião da AGB de Fortaleza em 1978.

... ou fomos e somos formados por professores que em realidade eram ou são mais militantes que acadêmicos ou pesquisadores, deformando completamente a formação geográfica dos alunos, muito frágil em termos de conhecimento seja da história do pensamento constituído na disciplina, seja do ponto de vista do método pois, como advogarei nesta reflexão, a Geografia brasileira, por não fazer discussões metodológicas e não ter coragem de encarar a dicotomia Geografia Humana e Geografia Física que permanecem em nossas grades curriculares, comete um sério desvio ético no processo de formação dos jovens geógrafos brasileiros, desanimados com seus cursos, segundo me revelam aqui e acolá e, pior, sem conseguir enxergar perspectivas de trabalho e contribuição na construção do futuro.

Esses dois caminhos prejudicaram em muito a produção do conhecimento geográfico brasileiro, atrasando nossa contribuição para o conhecimento do mundo e do Brasil, formando geógrafos frágeis do ponto de vista de sua erudição. Eles nos transformaram em profissionais com baixíssima visibilidade institucional e, pior, propiciam até hoje o que denomino processo de dissolução da Geografia.

Em minhas andanças pelo Brasil constato o interesse da juventude pela disciplina, mas a vejo completamente atônita, pois a Geografia lhe é apresentada com sua fragmentação infindável, que implica em uma perda de visão do rumo profissional dessa juventude. Busco animá-los com minhas falas, meu entusiasmo e minas contundências e, claro, com minhas indicações bibliográficas e metodológicas, para que ao menos tomem conhecimento dessa fragilidade dos nossos cursos, especialmente da graduação.

Pode ser que eu também tenha minha torcida, mas não a busco nem incentivo! E sigo solitária - não tenho instituições nem bandos para me juntar ou me defender. Pois, acredito, piamente, que o trabalho de pensar é solitário e não se dá nem em grupos, torcidas e, menos ainda, em redes, como tentam nos obrigar a fazer atualmente! Trabalho solitário não significa trabalho isolado. A sua finalidade é coletiva e sua prática também, mas sua responsabilidade é estritamente individual. Sempre foi e, sempre será! A cada um a responsabilidade pelo que cria, lidera, orienta e produz seja na ciência, no laboratório, seja em sala de aula, ensinando.

Apenas, faço um alerta sobre a lida com uma disciplina indispensável para o conhecimento do mundo do presente, mas não da maneira como anda sendo ensinada e produzida entre nós.

Peço a meus colegas que saiam de sua área de conforto! Que estudem muito e saiam da sua casinha. A realidade é interdisciplinar e exige de cada um de nós preparo enorme 
para praticá-la, multidisciplinarmente, a partir da nossa profunda competência disciplinar. E a Geografia tem sido apontada como uma metadisciplina!

Os enciclopedistas ou viajantes, como foram os geniais Humboldt, Saint-Hilaire e outros tantos que nos visitaram, descrevendo paisagens, praticando a geografia descritiva, de valor incomensurável para o conhecimento geográfico daqueles tempos tornaramse consultas históricas, com suas preciosas descrições. Hoje, diante da complexidade, aceleração, dinâmicas do mundo e, com o uso das novas tecnologias da informação, aquela prática foi superada! Agora precisaremos conhecer profundamente, epistemológica e metodologicamente nossa disciplina, para praticá-la no Século XXI, uma vez que podemos empiricirizar todo o planeta, como o faz em nossas mãos nossos celulares com a ajuda do Google e do GPS. Mas, o futuro será bem diferente daqueles tempos, como já o é o presente!

\section{Terr@Plural - É possível, ainda hoje, distinguir campo e cidade, rural e urbano?}

Para a compreensão que tenho da Geografia hoje e, de seu objeto de estudo, essa pergunta deveria ser formulada de outra maneira - por que tudo se urbanizou no mundo de hoje?

No entanto, dada à confusão que ainda existe entre os geógrafos e as dezenas de geografias que são feitas, diante da ausência de um edifício teórico metodológico que ainda persiste para muitos deles, essa pergunta carece de elaboração, pois o que permite que ela seja feita é não somente a diluição do objeto da nossa disciplina, como também uma questão de método. A análise dedutiva/descritiva que caracteriza o velho método geográfico, ainda praticado pela maioria dos geógrafos, dada a natureza do mundo do presente não se sustenta mais.

A urbanização transformou o dito "campo" em atividade agrícola, seja pela sua tecnificação, seja pela perversidade praticada contra o "camponês" que, ou virou operário agrícola e, como tal, nos dias atuais precisa manejar instrumentos tecnológicos cada vez mais sofisticados do que os seus habituais - ou ele vira lumpemproletário na agricultura ou, ainda, se transforma em favelado ou morador de rua na cidade!

Basta pensar no mundo e no espaço geográfico como totalidade dinâmica que constamos isso com enorme clareza, inspirando métodos mais eficientes e eficazes como gostam os neoclássicos, para compreender essa tradução moderna nas paisagens, da nova divisão territorial e internacional do trabalho.

É uma longa exposição sobre a necessidade que todas as ciências humanas ainda têm de se recriarem para dar conta das questões desta contemporaneidade e, consequentemente, atualizarem suas epistemologias, seus métodos e metodologias.

O campo e a cidade, não há dúvida, são distinguidos pelo olhar como paisagens distintas. No entanto, para sua compreensão, desde que o método - um sistema coerente de ideias - seja correto e contemporâneo, seus processos constituintes se identificam e se misturam, dadas as dinâmicas desta contemporaneidade. Por exemplo, pelas ações do capital financeiro na produção dessas paisagens, da ciência, da tecnologia e da informação, 
atividades nitidamente urbanas, que se juntam para a compreensão geográfica (não econômica, sociológica ou como fazem sempre os travestimentos); elas constituem aspectos dos distintos processos de urbanização, dados pelo modo de vida introduzido pelo capitalismo, em suas diversas aparências.

Como bem nos ensina o Professor Milton Santos, para lidar com o espaço geográfico, nosso objeto de estudo, há que aprofundar o conhecimento sobre a indissociabilidade entre sistema de objetos e sistemas de ações, como uma totalidade em movimento. Mas cuidado, totalidade não é o todo constituído de partes, como sempre a Geografia se apresentou, e como ainda pensam muitos que nunca estudaram filosofia! Há que estudá-la! E mais. Os reducionismos praticados por boa parte dos geógrafos pesquisadores que insistem em classificar e tipificar tudo atrasam o avanço do conhecimento geográfico. Hoje lidamos com processos, com formações territoriais. Nossa disciplina se dissolve, insisto nisso, por conta da zona de conforto em que estão instalados muitos dos pesquisadores geógrafos, que parecem não perceber a inoperância do trabalho descritivo, dos comodismos trazidos pela moda na pesquisa (o ambiental, o turismo, a inclusão, apenas para citar alguns) e as metáforas (a sustentabilidade, a segurança alimentar, etc. etc.), neste período histórico denominado de técnico-científico informacional. E, claro, a persistência daquilo que nós, os geógrafos colonizados que estudamos no exterior fazíamos, qual seja a de praticar a Geografia baseado, sempre, em autores estrangeiros.

Hoje, isso não se justifica mais, mas os fantasmas dos Lefebvre, Harvey, e outros insistem em nos assombrar... e dificultar nossa caminhada. Seus pensamentos dizem respeito às suas vivencias, às suas culturas, com a história de seu povo, que nada tem a ver com as nossas a não ser pelos laços que, tristemente, persistem das raízes colonizadoras que nos oprimem. Ainda que fossem ou sejam "de esquerda", ela é também histórica ... Quando é que aprenderemos a valorizar nossos intelectuais e pensadores? Eu atravessei esse processo todo e levei décadas para me libertar. Alerto sempre, respeitosamente, meus colegas com o entusiasmo que tenho de viver sendo geógrafa!

Tudo isso, do meu ponto de vista, aliado ao entendimento de uma discussão que jamais fazemos sobre ética profissional e, por consequência, a missão social do geógrafo que, apesar de mal resolvida pelos nossos equívocos epistemológicos, ou melhor, diluída pela diminuição da atuação do geógrafo como protagonista nas discussões de questões centrais contemporâneas onde o espaço geográfico é o principal protagonista, palavra tão cara aos neoliberais de direita e esquerda. Claro, para quem usa cenário e ator na explicação científica, o protagonismo completa a cena de falseamento da existência como teatro e não como realidade!

Os geógrafos são entrópicos, só falam entre si e se aplaudem, mutuamente, organizando-se em verdadeiras torcidas, cujo chefe é sempre um professor "querido" e amigo mais dos alunos do que de seus pares, que o fazem crescer, quando a crítica existe e é honesta ...

Reparem que não desenvolvo aqui, por cansaço, a mais arcaica dicotomia entre Geografia Física e Humana, que prevalece em nossas grades curriculares, reveladoras desse atraso epistemológico e científico no qual ainda estamos metidos. E ele só não entra 
em nossas pautas de encontros e congressos por incompetência nossa, para não misturar torcidas e destruir os sistemas de poder nos quais lamentavelmente nos organizamos.

Por isso, retomando ao que introduzi acima: não é apenas pela aparência e pela forma que as paisagens se apresentam é que norteiam o nosso trabalho!!! Isso é muito raso e revela uma superficialidade de erudição e de capacidade de compreender a totalidade em movimento, que é nosso objeto de estudo e da nossa disciplina. E esse objeto tornou-se histórico, queiramos ou não. Histórico pela sua historicização, desculpem-me a tautologia, mas o espaço geográfico se historiciza pelo uso do território.

E 'uso' é resultado de práticas sociais, que no capitalismo têm sido entendidas como relações entre classes sociais, clara e nitidamente expressas pelas paisagens. Esse uso do território - e é bom lembrar que, exatamente por isso, o território para a Geografia só existe quando usado, praticado, historicizado, pois produto - esse uso - de relações sociais que determinam as paisagens urbanas e agrícolas, e não mais rurais e urbanas, ou cidade e campo.

A ideia de totalidade e a compreensão do espaço geográfico proposta por Milton Santos, com o uso de suas categorias de análise de forma, função, processo e estrutura, quando aceita e praticada, ajuda também a elaborar a crítica sobre essas dicotomias reveladas na questão que me foi proposta. E mais, os conceitos de circuitos espaciais produtivos e círculos de cooperação atualizam e matam essa charada!

Tristemente, esse autor é vastamente citado, mas não lido e, logo, não utilizado corretamente, nem as necessárias críticas que sua obra, como a de qualquer autor, merece. As pouquíssimas que existem são levianas e superficiais ... As citações, curiosamente, refutam completamente o método usado pelo autor que o cita, mas este não percebe que dá um "tiro no próprio pé"! Muito triste o que acontece hoje, com parte dos trabalhos dos geógrafos brasileiros!

Concluindo, a partir do que rapidamente busquei fundamentar, no pouco tempo disponível de uma entrevista: a Geografia precisa compreender as paisagens e não apenas descrevê-las abandonando, simplesmente, o espaço geográfico e voltando a um positivismo ou neopositivismo formalista. Nenhuma paisagem pode continuar a ser entendida sem a compreensão das dinâmicas do mundo atual, essa totalidade em movimento. Nesse sentido as velhas Geografias Agrária e Urbana foram ultrapassadas por essa dinâmica, pois o mundo todo urbanizou-se, no sentido de que o modo de vida urbano tomou conta dessa totalidade, seja para o benefício de poucos, seja com perversidade para a grande maioria que se movimenta pelo mundo simplesmente para viver em paz, com dignidade. Então os geógrafos, para dar conta disso tudo, dessas dicotomias que precisam ser superadas e compreendidas a partir do rigor do método geográfico, dialogando com outras disciplinas e não continuando a usar os seus conceitos como camisa de força para a compreensão do espaço geográfico, como a descabida formulação de "produção do espaço". O espaço não se produz, o que se produz é o uso do território historicamente determinado, materializado visivelmente pelas paisagens. Campo e cidade, rural e urbano estão emprenhados no mesmo movimento da essência deste período histórico agonizante, dominado pela ciência pela técnica e pela informação. Aparência, essência, estrutura e processo são os 
ingredientes essenciais dessa totalidade em movimento que é o espaço geográfico, nosso objeto de estudo.

\section{Terr@Plural - Quais as diferenças e particularidades entre cidade e urbano?}

Volto a Milton Santos (1992: p. 241-244) ${ }^{1}$ que em uma conferência feita em um Seminário organizado pelos arquitetos em Salvador (Bahia) os define magistralmente. Eles são ainda muito usados por arquitetos, urbanista e geógrafos apenas como palavras e não como conceitos, tamanha é a confusão existente nos textos. Milton Santos nos ensina: "Na realidade duas coisas estão sendo confundidas graciosamente, alegremente: a cidade e o urbano. Há duas coisas que se pode fazer separadamente ou conjuntamente: a história da cidade, a história do urbano. O urbano é frequentemente o abstrato, o geral, o exterior. A cidade é o particular, o concreto, o interno". E, prossegue Milton Santos: "O estudo da cidade exige a necessidade de articular-se o conceito de espaço, antes de começarmos nosso trabalho sem o que, nem mesmo saberemos do que vamos tratar. Assim será inútil querer fazer-se história urbana porque os resultados serão confusos. O espaço é uma categoria de análise histórica, e, por conseguinte, o seu conceito muda, já que se acrescentam novas variáveis no curso do tempo. Temos, então, de obter o mínimo de acordo em relação ao que o espaço é, ainda que isso possa parecer extremamente difícil." (1992, idem).

Como em nossa disciplina até hoje muitos lidam com o espaço da maneira como bem entendem - no mínimo como Físico ou Humano - os prejuízos que temos para fazer avançar o conhecimento são imensos. Somos uma disciplina com dezenas de objetos, em cujos desenvolvimentos o espaço geográfico desaparece ao virar uma funcionalidade, uma utilidade buscada em outras disciplinas. A isso denomino dissolução da Geografia, dada sua fragmentação e nossa incapacidade em lidar com o seu único objeto - o espaço geográfico - e não o urbano, a cidade, a indústria, o comércio, o turismo e pior até - a cultura esfacelada em religião, odores, carnavais etc, etc. Parece que a função ética do conhecimento abandonou a Geografia depois de Vidal de La Blache, Pierre George, Michel Rochefort, entre alguns franceses, e Milton Santos aqui entre nós. Milton é odiado porque exige competência para discuti-lo, mas é oportunisticamente usado!

Lamentável essa revelação da falta de erudição dos geógrafos, em geral, para poder praticar uma disciplina tão importante e necessária nesta contemporaneidade como a Geografia. Não há tempo aqui neste espaço para expor meu avanço com relação às colocações de Milton e resolver o problema da fragmentação com um método geográfico bem concebido. O espaço geográfico é instância, nos ensina o Milton. A categoria de análise histórica, social, é o território usado. Este é o espaço geográfico (instância), que quando historicizado torna-se um sub-conceito deste - o território usado (o uso do território é o produto histórico das relações sociais). Mas isso está escrito no livro que estou finalizando e lançarei ainda este ano. Discordo de Milton quando os tratam - espaço geográfico e

1 SANTOS, Milton. A Cidade e o Urbano como Espaço-Tempo. In: FERNANDES, Ana; GOMES, Marco Aurélio A de F. Cidade \& História. Salvador: ANPUR, 1992. 
território usados como sinônimo! O uso do território de cada país, nação, revelador de suas culturas (ai aparece a cultura, nas formas, processos, conteúdos e estruturas) que balizam as relações sociais. Acrescente-se a isso a confusão entre os conceitos de desenvolvimento urbano, urbanização, tratados numa imensa produção de textos superficiais, lidados muitas vezes, inclusive, como sinônimos. Neste sentido escrevi um texto a convite do CNPq, para produzir a avaliação dos bolsistas, que tomo a liberdade de recomendar a leitura, para quem possa se interessar ${ }^{2}$. Não há como fazer avaliações sem expor os conceitos que são utilizados para fazê-la. Tem sido muito difícil a construção cientifica da Geografia, para dar a ela o status de ciência e não de jornalismo vulgar, descritivo, apenas ... Faço sempre provocações para buscar gerar um debate ... Tem sido em vão! Não há debate na Geografia! Há torcidas organizadas, que não debatem, mas se ignoram mutuamente! Fácil identificálas na prática política dos geógrafos e suas disputas pelo poder, nos departamentos, nas sociedades cientificas e associações. $\mathrm{O}$ poder de grupos se repete alternadamente, regularmente, num giro rítmico, regional e de programas. Difícil alterar a ordem da lista! Com todo respeito, mas muitos sabem disso e não podem dizer... Não tem cabelos brancos! Evidentemente que toda regra tem exceção! Eu sempre as reconheço com meus gestos...

Terr@Plural - No processo intenso de urbanização em nível mundial, quais são as especificidades do caso brasileiro?

Confesso a vocês que deixei de ler e acompanhar o que se escreve no Brasil diante da pobreza dos escritos, dos autores estrangeiros inspiradores dessas produções (basicamente Henri Lefebvre e David Harvey...) e da falta de compromisso com a produção de uma pequena teoria da urbanização brasileira, na qual busquei contribuir teorizando e criando o conceito de verticalização usado posteriormente por alguns orientados meus. Como Nádia Somek (estudando São Paulo), Janete Coimbra (estudando Belém do Pará), Cesar Miranda Mendes (estudando Maringá... se não me falha a memória), estimulados provavelmente por um artigo que escrevi sobre esse tema em 1981, para uma reunião da Comissão de Geografia Urbana da UGI - União Geográfica Internacional, que se reuniu em Brasília. Neste apresentei a duras penas esse paper ao grupo à época dirigido pelo colega execrado pela direita que sempre tomou e toma conta da UGI.

É preciso antes de tudo compreender que no seu sentido correto o conceito de urbanização como tal vem do urbanismo e é expresso pelo processo de definição de loteamentos, forma amada pela especulação imobiliária que cria lotes, tornados mercadorias em mercados sempre accessíveis à uma minoria - os permanentes déficits habitacionais não me deixam mentir - perdurando um grave problema que julgo estar sendo encaminhado

2 SOUZA, Maria Adélia. Urbanismo. In: Avaliação \& Perspectivas. Brasília: SEPLAN/CNPQ, 1982. Vol. 1/Sinopse. p. 478489. Eu representava no Conselho Assessor do CNPq a área de Arquitetura, Urbanismo e Planejamento Urbano. Daí a solicitação do Coordenador de Avaliação, na área de Ciências Sociais Aplicadas, o economista Prof. Flávio Rabelo Versiani. $\mathrm{Na}$ época, o CNPq produziu separatas dos textos de cada uma das áreas e distribuiu fartamente para as sociedades cientificas, associações, departamentos e faculdades. Ele teve o mesmo espírito daquele de Milton sobre a cidade e o urbano, escrito por ele posteriormente em 1992, qual seja lidar com conceitos e fundamentar as disciplinas com as quais trabalhamos. 
de forma equivocada inclusive pelos militantes dessa causa. Mas isso é uma longa, complexa e quase impossível discussão, dada a história da pesada militância nela envolvida ...

Lotear é urbanizar, que tem o sentido de mercantilização da terra e não da aquisição do modo de vida urbano. Mas esse sentido de confusão entre o processo de urbanização e o processo de desenvolvimento urbano, ou seja, a vinculação da vida urbana como modo de vida, é intensamente usada a partir do século XX. Faço essa distinção apenas para revelar como os estudos urbanos navegam em terrenos movediços uma vez que fragilmente constituídos conceitualmente até hoje.

A Geografia está ainda, por fazer esse esforço, que poucos entre nós realizamos, buscando a identidade do nosso processo de desenvolvimento urbano e deixando para os urbanistas a sofisticação do processo de urbanização. Processo aliás sempre expresso por uma enorme dívida social - não se urbanizam as periferias, e sim os loteamentos de alto padrão. Urbanizar significa dotar o território de usos que devem principiar pelos equipamentos e serviços de interesse coletivo mais básicos (água, esgoto, luz, telefonia, galerias pluviais, coleta de lixo, entre outros) até os mais sofisticados. Essa discussão teórica nunca é feita e a empiricização leviana sem teoria é a que prevalece, empregando conceitos que não se aplicam a nossa realidade. Teorias alheias a nossa história não passam de ideias soltas, generalidades superficiais que por não colarem com nossa realidade, nunca viram conceitos, ideia testada no real. A velha questão do teórico/prático que pouco tem importado aos geógrafos, sempre travestidos em cientistas políticos, economistas, sociólogos, antropólogos, biólogos ... daí o espaço geográfico e o território usado não aparecerem como categorias de análise em seus trabalhos. Insisto nisso!

Diante dessa nossa precariedade teórica, permanecemos ainda no início do século XX. Eu ousaria propor que o processo de desenvolvimento urbano brasileiro (o processo de urbanização deixo à cargo dos urbanistas) apresenta pelo menos três especificidades, além daquelas que outros poderão ajudar a identificar:

A rapidez com a qual se deu e ainda se dá o processo de formação das cidades tanto no sentido oficial do termo como no sentido de aglomeração da população usando territórios contínuos, quase sempre para sobreviver. No sentido oficial proposto pelo FIBGE (distrito sede do município), há ajuntamentos populacionais enormes que permanecem distritos, e pequenos que tornaram-se cidade, pois a nomenclatura conceitual do processo de desenvolvimento se vincula estritamente a política, muito mais do que a qualquer outro aspecto da vida social. Há trabalhos interessantes explicitando esta tese, com a qual lidei a propósito do Estado do Paraná, no início dos anos 1960. Não há tempo aqui para comentar sobre a parafernália tipológica do FIBGE nos últimos anos para tipificar esse processo: aglomerações urbanas, áreas urbanizadas etc. como se o espaço geográfico não fosse uma totalidade e pudesse ser fragmentado em tipos. Velhas teorias prevalecendo no mundo novo, oficialmente! Busquem as sugestões propostas para a realização do Recenseamento de 2020, se ele for realmente feito! Outrora existiam comissões compostas por inúmeros agentes usuários de informações oficiais, que se reuniam para organizar o conteúdo das informações a serem aplicadas durante o recenseamento. Era uma verdadeira guerra política! Tive a honra e o privilégio de representar o governo de São Paulo nessa 
Comissão e ter ajudado a incluir questões preciosas, que as feministas de hoje certamente desconhecem..., mas esta também é outra história ...

Um segundo aspecto que dá especificidade ao processo de desenvolvimento urbano brasileiro (veja que não respondo a pergunta feita, por considera-la equivocada, ou então mal formulada para uma geógrafa que busca rigor cientifico e conceitual) é o acelerado processo de agigantamento das cidades, que passamos a denominar de metropolização - outro conceito dolorido por suas origens e que nenhum de nós buscou corrigir. Ao contrário, eu mesma, quando com uma equipe de colaboradores formulamos a primeira política de desenvolvimento urbano para o Estado de São Paulo, forjamos o conceito de macrometrópole, uma enorme área 'urbanizada' que, nucleada por São Paulo, alcançava São José dos Campos no vale do Paraíba, Campinas, Sorocaba e Santos, no litoral. Chamo a atenção que, dado o significado político (instância social) do espaço geográfico metropolizado pela sua complexidade, intencionalidade e extensão, a lida política desse mega espaço urbanizado ainda é extremamente dificultada. Não se fala em poder metropolitano, por mais óbvio que a metrópole decorra de um fantástico processo de conurbação. A região do $\mathrm{ABC}$ na metrópole paulista, a baixada fluminense no Rio de Janeiro, como tantos outros exemplos existentes no Brasil, caracterizam esses processos de urbanização conurbados. O lamentável é que, como a compreensão desses processos se dá por questões de antagonismos sociais, logo políticos, ao invés de encarar essa dificuldade e resolver os problemas criados para a população, especialmente a pobre, nossos técnicos e cientistas optaram pela velha e já derrotada escola analítica ao criar tipos. Aí inventam coisas sem sustentação como aglomerados urbanos e outras patifarias conceituais. Tudo isso, porque o estatuto de região metropolitana ou metrópole regional dá à cidade que o adquire uma série de privilégios no acesso a benefícios governamentais importantes. Eu mesma anos atrás sugeri que a cidade de Sobral fosse considerada uma metrópole regional. Felizmente, dez anos depois minha ideia foi acolhida e Sobral tornou-se metrópole por uma lei aprovada pela Assembleia Legislativa do Ceará, recentemente! É obvio que essa questão é de ordem política, mas política territorial e não política de interesses privados. Lembremos que o espaço geográfico é também chamado por Milton Santos de espaço banal, espaço de todos. Quando historicizado vem a significar que os usos do território precisam ser democratizados e dado acesso a todas e todos, as instituições, organizações e pessoas. Com isso, o povo da rua deixa de existir, a favela deixa de existir, e por aí vai... Essa é a importância do conceito e não da tipologia à qual muitos ainda recorrem nos estudos geográficos. O uso do território, insisto, é um direito inalienável a existência humana, e por ser humana precisa ser digna! É disso que se trata! A Geografia lida com a vida humana na superfície do planeta, essa é sua função essencial. Logo, ela não pode prescindir da Ética ... Ética do conhecimento, pelo menos!

Em decorrência desses dois intensos processos, extremamente importantes, há um terceiro que avança, que é o processo de criação de novos municípios, logo, de novas cidades. Não fora a natureza do desenvolvimento exigido pelo capitalismo, este deveria ser também o processo básico de democratização da sociedade brasileira, a base territorial da democratização. Mas, quando se fala em democracia, não se fala em território, mas 
apenas em gestão governamental: da economia, da dívida, dos tributos, das privatizações ... e o território está ausente. Logo, o cidadão e a vida humana estão ausentes, por mais democratas que sejam os políticos ou os técnicos que os assessoram, inclusive alguns poucos até sendo geógrafos. Aliás, é bom que se diga, somos raros aqueles convidados a assessorar políticos na perspectiva de um processo democrático! Não somos habilitados a lidar com a totalidade em movimento, uma vez que o espaço geográfico não é considerado como instancia para a grande maioria dos geógrafos, mas sim palco onde se organiza e ordena a sociedade e suas atividades. É uma ideia conservadora, eu diria mesmo reacionária, que ainda preside o ensino e a pesquisa na grande maioria dos departamentos de Geografia e programas de pós-graduação! Se houvesse organização e ordenamento levados a cabo até a última consequência os pobres já estariam mortos, pois não são sujeitos sociais desse processo. Aliás, as paisagens das periferias metropolitanas não me deixam mentir!

Longa e complexa essa conversa. Tenho dificuldades cada vez maiores de fazê-la pois na Geografia que faço essa questão não cabe. Fiz um exercício crítico para demonstrar como os problemas a serem enfrentados pelos geógrafos são enormes. Há que ultrapassá-los atualizando o método geográfico e sabendo de fato o que é a Geografia e como ela se funda nesta contemporaneidade como ciência. Caso contrário, ela continuará a se dissolver ...

Terr@Plural - Quais seriam os critérios/variáveis mais importantes para a conceituação de cidades grandes, cidades médias e cidades pequenas, para além do dado quantitativo relacionado ao número de habitantes? Nessa perspectiva como podemos avaliar a emancipação de distritos?

Penso que parte desta questão já tratei na resposta anterior. Como advogo a tese de que a categoria de análise social de que dispõe a Geografia para que ela se faça é o território usado, eu estou propondo que o território usado seja discutido sob a ótica da política. Quem, onde, como e por que se usa o território? O território precisa ser considerado uma categoria de análise social, logo política. Neste sentido a discussão é qualitativa e politicamente feita, em função dos interesses da Nação. Não há tipos nem padrões que sustentem essa discussão, logo nem à essa pergunta! A discussão sobre a criação de novas cidades ou aquela de emancipação de distritos passa pelo mesmo processo, de uso do território, mediado pela questão política da Nação e não do vereador, deputado, senador, governador ou presidente de plantão. Para tanto, existem os plebiscitos. Mas aplicam-se plebiscitos no Brasil sem que tenhamos explicitado um projeto de Nação territorialmente construído. Só se constroem projetos econômicos fantasiados de discurso democrático! Mais da metade da população brasileira vive dos restos da atividade política, tanto quanto o emprego e o consumo. Como discutir o futuro da nação sem pensar nas pessoas lá onde elas vivem, nos seus lugares, dentro das suas localidades, sejam elas distritos, cidades ou metrópoles! A discussão geográfica foi sufocada pelo capitalismo e nós os geógrafos embarcamos nela e estamos afogados até o pescoço! Milton Santos foi um dos que tentou tirar-nos do fundo do poço... e o resultado ainda é pífio! 
Terr@Plural - Qual sua definição de cidade média? Esse termo teria a força de um conceito?

Há décadas espero por esta oportunidade de falar acadêmica, científica e politicamente sobre um dos maiores equívocos dos geógrafos. Explico-me. O programa de cidades médias foi um Programa de Governo do General De Gaulle - do IV Plano de Aménagement $d u$ Territoire, se não me falha a memória, coordenado por meu orientador, mestre a amigo Michel Rochefort, ilustre e competente geógrafo francês do século passado, com quem tive o privilégio de conviver por quase meio século e, convidada por ele, acompanhei de perto as discussões desse Plano. O Programa de Villes Moyennes era central para atingir o grande objetivo do plano territorial de descentralização do poder de Paris com relação ao resto do território francês. Há um livro escrito sobre isso Paris e o Deserto Francês.

Chegando no Brasil para fazer minha pesquisa de doutorado e, posteriormente, sendo convidada por Jorge Francisconi para ajudá-lo a coordenar a elaboração da I Política Nacional de Desenvolvimento Urbano do Brasil e, como minha equipe da Coordenadoria de Ação Regional da Secretaria de Economia e Planejamento do Estado de São Paulo, com o entusiasmo da minha juventude e falta de profundo espírito crítico, propus a meus colegas da política urbana que construíssemos o Programa de Cidades Médias para São Paulo e para o Brasil, pois em ambas as escalas a macro concentração urbana era diagnosticada, exatamente, como no caso de Paris. Apenas ignoramos que as histórias, os costumes, a 'madurês' política dos povos eram completamente diferentes.

E essa imensa besteira foi feita. Foi um sucesso oportunista para os políticos do regime e, evidentemente, para os profissionais tão oportunistas e carreiristas quanto, que sem pensar o que faziam transformaram um produto político, imaginário, em um objeto cientifico e, mais sério ainda, virou Programa de Pós-graduação outorgando títulos de doutores e mestres e, em outros casos, projeto de avaliação da ação do governo feito por colegas desprevenidos, para ser elegante. Fiz minha autocrítica publicada em livro dirigido por Csaba Deák e Sueli Ramos Schiffer, ilustres colegas da FAU USP, intitulado O Processo de Urbanização no Brasil, editado pela EDUSP em 1999.

Como se faz pesquisa sem revisão bibliográfica no Brasil, a Ética do Conhecimento entre nós é desconhecida, e essa farsa das cidades médias foi sendo perpetuada. As coisas se passam como partidas de futebol, há sempre que ganhar e as torcidas (alunos ansiosos por obter diplomas e professores enriquecerem currículos) estão sempre organizadas e ... enganadas. Toda vez que visitava a França fui motivo de chacota pelo fato de meu país ter criado Programas de Pós-Graduação sobre Cidades Médias, uma aberração, reveladores de um duplo desconhecimento: um, teórico metodológico vinculado a um quantitativíssimo ultrapassado - as médias só existem para os ignorantes, já dizem por ai - e um total desconhecimento de metodologia e epistemologia geográficas, ignorando o que é uma ciência e seu objeto e que ela - a ciência - só pode ser criada a partir do real concreto e da práxis. Pena ver a Geografia e o Planejamento Urbano implantando essa besteira e outorgando título de doutores, com o beneplácito da douta CAPES, que em realidade somos nós! 
Agradeço muito a Terr@Plural por esta pergunta, há muito tempo tenho isso se engasgando na garganta! Ou as pessoas não leem o que se escreve no Brasil, ou não acompanham as políticas governamentais, ou ... entendam como quiserem, os leitores!

O fato é que se trata de um tema conhecido de todas e todos nós e a tal Cidade Média sempre foi execrada por mim, pelo direito que tenho de fazê-lo no Brasil, pois criei o monstro! Lamento o fato desse enorme equívoco ter crescido no Brasil pelo desconhecimento dos fatos ou pela falta de coragem de me ouvir a respeito, pois sempre foi público e notório a minha autoria sobre o Programa de Cidades Médias nos Governos Federal e Paulista. As duas coisas são inadmissíveis para um professor e pesquisador!

Terr@Plural - Existe a possibilidade de conciliar o processo de urbanização com o chamado "Desenvolvimento Sustentável"? Ou essa terminologia se resumiria a um mero discurso político/ideológico, uma metáfora sob a hegemonia do sistema vigente?

Eu já vinha achando que esta não era uma entrevista, mas uma provocação da Revista, a quem agradeço novamente, por ter tido a coragem de me entrevistar, pois sou o personagem podre da Geografia Brasileira, para muitas e muitos! Não frequento suas atividades e nem sou convidada, exceto quando fui dirigente com Milton Santos da ANPUR e da ANPEGE, cuja primeira ata eu, pessoalmente, registrei em Cartório, pois fomos os instituidores dessa última douta associação.

Depois disso, como sempre me dizia Milton, fomos apagados da lista dos frequentadores ... Mas, em 2017, quase 20 anos depois, a convite de Dirce Suertegaray, então Presidenta da ANPEGE, aceitei receber uma homenagem, acompanhando meu querido amigo Carlos Augusto de Figueiredo Monteiro, que já não viaja mais sozinho ... Pedindo mais uma vez desculpas aos meus colegas é preciso que os geógrafos aprendam que homenagem é uma honraria individual e que não deve ser feita como "baciada no final da feira", como sempre é feito entre nós. Não se divide homenagem com ninguém! Tenham a coragem de escolher e homenagear que quiserem, mas, individualmente, como se faz no mundo inteiro (ou se fazia, pois o mundo muda sempre para pior!!). Não tem cabimento homenagear um professor como Carlos Augusto, com outros tantos, inclusive esta que aqui se manifesta, correndo riscos sérios! Percebemos a sutileza da homenagem feita pela ANPEGE e pela Diretoria da ANPEGE ... isso não é bonito, desculpem-me! Não tenho medo da divergência. Tenho medo da ignorância e do desconhecimento das liturgias acadêmicas milenares, que significam respeito a história do passado e das instituições importantes que perduram... à direita ou à esquerda, não importa. Elas perduram - as Academias - e com seu trabalho fizeram e fazem uma linda travessia em benefício da vida como um todo no Planeta.

Agora estou convencida, com esta derradeira questão de que se trata de fato de uma provocação rsrsss...

Vejam minha situação. Detonei o conceito de urbanização logo no início da entrevista, lamentei a besteira das Cidades Medias terem constituído programas de pós-graduação e tenho escrito e lamentado o uso da metáfora sustentabilidade, como tantas outras que 
valsam nas bocas de uma esquerda neoliberal, como dizia mestre Darcy Ribeiro em conversas informais. Tudo isso revela, no meu entender, o despreparo dos professores e cientistas brasileiros no que tange a produção do conhecimento e da prática política. Despreparo, quando digo e aponto, de todas e todos nós, tanto pelo avassalador processo de colonialismo cultural a que somos ainda submetidos, e do qual muitos não conseguem se libertar, quanto pela juventude da nossa precária vida e ensino universitários. Ou fazemos essa autocrítica ou não nos tornaremos livres e soberanos nunca!

A sustentabilidade tem história, mas não terei tempo de contá-la nesta entrevista, e nasce no Banco Mundial, através de um seu renomado assessor que andou muito pelo Brasil testando a sustentabilidade em favelas ... e assessorando governos, inclusive o de São Paulo.

Tenho sido crítica contumaz do uso de metáforas que se tornam conceitos e se prestam, equivocadamente, ao trabalho científico, mas, sobretudo, a formulação do discurso político, onde tudo cabe. A ciência não é isso, e nem tem a finalidade de busca do poder, da celebridade, mas da manutenção da vida - produzir conhecimento e ciência é coisa séria. Mas, as metáforas invadiram de uma tal maneira a ciência e a política, desde os anos 1970, que cumpriram sua missão de dar mais folego ao capitalismo, com o discurso montado de amor a natureza, a Terra (como se ela precisasse dessa insignificância e não soubesse com seus movimentos telúricos regular-se a si própria) e a farta distribuição de recursos a quem se dedicasse ao tema ambiental. Virou uma febre! Ou uma epidemia que ainda resiste com seus vírus espalhados por aí...

O resto é discurso político. Falar em sustentabilidade quando tudo se desmancha no ar; segurança alimentar quando o agronegócio comanda economias frágeis e pobres do planeta como a brasileira, toda nas mãos de multinacionais; inclusão social no capitalismo, que é em sua essência excludente, pois dependente do mercado, sendo a desigualdade seu motor; a questão ambiental tratada equivocadamente, pois o ambiente se dá em escala doméstica, domínio da intersubjetividade, âmbito da Arquitetura! Todas essas metáforas invadiram o processo o processo científico e político. E isso não ajuda nem o processo de conhecimento, nem o país, a progredirem e ajudar a nação a resolver seus problemas e conquistar sua soberania, nem a tornar o mundo melhor.

O 'meio natural', nosso precioso conceito avacalhado pelos técnicos do Banco Mundial desde Estocolmo no início dos anos 1970, foi substituído pelo retorico e confuso 'Meio Ambiente', completamente sem sentido para a Geografia, mas que foi abraçado pelos colegas incautos que difundiram esse sofisma. Pensem bem que combinação: o conceito de meio natural, nosso primeiro conceito complexo, oriundo da dita Geografia Física, qual seja o resultado da combinação entre vegetação, clima e solo, casado com ambiente, conceito que vem da fenomenologia e tão caro aos arquitetos, seus produtores maiores! O que significa em realidade Meio Ambiente, cientifica e rigorosamente falando? Nada! Um falso conceito, um embuste epistemológico! E sua sustentação insustentável é dada pela sustentabilidade. Tão confusa quanto essa frase que acabo de escrever... essa é a clareza do discurso que conduz o besteirol daí resultante. Por favor, pensemos um pouco e sejamos sérios. 
Caso alguém se interesse por esse texto, intitulado Meio Ambiente e Desenvolvimento Sustentável. As metáforas do capitalismo, ele foi publicado pela corajosa Revista Cronos, da UFRN, em seu volume 10 de janeiro de 2013, fazendo parte de um Dossiê intitulado Meio Ambiente e Sociedade. Consulte-o e se discordar, escreva e refute! Apenas assim caminharemos cientificamente. Aí está, nesse artigo, minha resposta a esta provocação feita pela entrevista, de forma mais completa e com argumentos que julgo consistentes.

Sou muito grata a meus colegas da Terr@Plural pela oportunidade, especialmente na pessoa do professor Sergio Negri, que me contatou para participar desse importante Dossiê sobre Cidades Médias e poder, finalmente, exibir minhas críticas a essa ideia. Jamais tive a oportunidade de tornar pública minhas críticas que considero importantes, sendo a "mãe da criança" nascida no Brasil. E foi uma enorme besteira da qual já me penitenciei. E fiz minha autocrítica que está publicada.

Estou à disposição para todo e qualquer esclarecimento que se fizer necessário. Nossa estrada será longa e penosa, como aquela do nosso país. Aliás, seu caminho é ditado pela qualidade do conhecimento que ensinamos e produzimos sobre ele.

Forte abraço a todas e todos, geógrafas e geógrafos brasileiros! 